\title{
A Comparative Study on Tensile Strength, Hardness, and Microstructure at ST.42 Steel Plate Welded with Electric and Acetylene Welding
}

\author{
Badaruddin Anwar \\ Universitas Negeri Makassar \\ Makassar, Indonesia
}

\begin{abstract}
This study aims to determine the physical and mechanical properties of the steel plate welded ST.42 after using electric and acetylene welding. It is also to know the difference in tensile strength, hardness, and microstructure on ST.42 steel plate welded in both welding process. The research data was obtained with experimental methods by comparing the tensile strength, hardness, and microstructure for both welding process and was tested by using universal testing tool such as Vickers hardness test and digital microscope. Data were analyzed with descriptive statistics and inferential statistics. The object of this study was ST.42 steel available in the market. Results of the data analysis showed that there is no significant difference between the tensile strength, Vickers hardness numbers, and the microstructure of the steel grain pearlite and ferrite results for both electric and acetylene welding on steel plate ST.42. The magnitude of the tensile strength of electric welding had maximum tensile strength of $361.1460 \mathrm{~kg} / \mathrm{mm} 2$ with a maximum tensile force of $115.5667 \mathrm{~N}$. The amount of tensile strength through Oxyacetylene welding had a maximum tensile strength of $58.2500 \mathrm{~kg} / \mathrm{mm} 2$ with a maximum tensile force of $18.6400 \mathrm{~N}$. The magnitude of Vickers hardness number of electric welding was in average of $936.5443 \mathrm{HV}$. On the other hand, Vickers hardness number of Oxyacetylene was in average of $\mathbf{9 0 2 . 5 2 2 0}$ $\mathrm{HV}$. The results of microstructure through electric welding were $\mathbf{6 6 . 8 4 9 6} \boldsymbol{\mu \mathrm { m }}$ for steel grain pearlite and $29.3485 \mu \mathrm{m}$ for steel grain pearlite. The amount of those of Oxyacetylene welding were $58.5267 \mu \mathrm{m}$ for steel grain pearlite and $29.3585 \mu \mathrm{m}$ for grain ferrite steel.
\end{abstract}

Keywords-tensile strength; hardness; microstructure; electric; acetylene welding

\section{INTRODUCTION}

For several years, welding has become an important factors in industrial worlds. It is not only a process that has been used to join several parts especially in metal form but also has been used for repairing damaged parts of products. In general, welding is defined as the process of switching between two or more metal parts by using thermal energy. The energy is required to heat the base material to be joined and welded wire as filler material. According to Korte it is one way to connect solid objects using melt by heating [1]. Kalpakjian and Schmid explained that welding is one of grafting techniques with the heat [1]. It was done in the administration of the metal and the electrode by connecting the electric current between the electrode and the base metal (workpiece). However, several welding processes have been developed recently [2]-[5]. The advanced of these process were made to serve some purposes such as to reduce product weigh and cost efficiency. Park et.al stated that the best welding voltage is between 15-20 volts to the electrodes wrapped in thin and 20-40 volts to the electrodes wrapped in thick, and for welding required 60-140 amperes of electric current [6]. The heat of electric welding arc can reach 7500$10000 \mathrm{~F}$.

Welding by using Oxyacetylene is a manual welding process by heating the metal surfaces or fusing to melt by Oxyacetylene gas flame through the combustion gas $\mathrm{C}_{2} \mathrm{H}_{2}$ with $\mathrm{O}_{2}$ with or without filler metal. By advancing method and the discovery of liquid which can minimize the cost of oxygen, this method has gained its popularity for the past ten years [7]. In this process, oxygen gas is mixed with Oxyacetylene gas. The combination of oxygen and acetylene in earlier time of welding research has been proved in increasing the temperature of flames. The higher temperature of flames that produced during welding process, the easier way to localize the melting of material. Ordinary flame temperature can reach $3500^{\circ} \mathrm{C}$

In Oxyacetylene welding; there are three types of flame obtained. They are a neutral flame, oxidizing flame, and carburizing flame [8]. Both oxidizing and carburizing flame produce flames that contain more oxygen or acetylene. These two flames are not required in any welding jobs. Only neutral flame that contains both gases in balanced amount commonly required in welding process. This flame appears without any additional pressures. Therefore, it is highly expected that only neutral flames are produced during this process. 


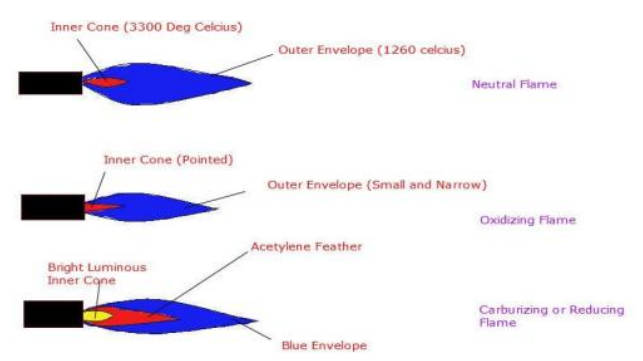

Figure 1. Three types of flames

In the weld joint tensile test, the specimen is burdened with the load and the heat is increased gradually until the test rod broke. The tensile occurs as the force per unit area. Then, the characteristics of the force can be calculated by the following equation:

$$
\sigma=\frac{F_{\max }}{A_{0}}
$$

Description: $\sigma=$ tensile stress $(\mathrm{kg} / \mathrm{mm} 2)$; Fmax $=$ maximum $\operatorname{load}(\mathrm{kg}) ; \mathrm{A} 0=$ initial cross-sectional area $(\mathrm{mm} 2)$.

Comparison between the extension of the length and the initial length of the specimen called a strain. Strain mathematical equation is:

$$
\varepsilon=\frac{L-L_{0}}{L_{0}} \times 100 \%
$$

Description: L0 = initial specimen length $(\mathrm{mm}) ; \mathrm{L}=$ length of specimen after loading $(\mathrm{mm})$

At the time of tensile testing done, if the withdrawal of the material continues to break up we will get a profile of traction in the form of a graph/curve showing the relationship between the pulling force to the change in length. The focus of attention of this test is the maximum capacity of these materials withstand the load or tensile stress maximum.

Moreover, Vickers hardness number (VHN) is defined as the load divided by the surface area of the indentation [9], [10]. This testing is a standard test for microhardness test which normally conducted for small part or thin sections. In practice, this field was calculated from measurements of the microscopic diagonal length of the trail. VHN can be determined from the following equation:

$\mathrm{VHN}=\frac{2 \mathrm{P} \sin (\theta / 2)}{\mathrm{d}^{2}}=\frac{(1,854) \mathrm{P}}{\mathrm{d}^{2}}$

Description: $\mathrm{P}=$ load used $(\mathrm{kg}) ; \mathrm{d}=$ average diagonal length $(\mathrm{mm}) ; \theta=$ angle between the surface of the diamond face $=$ $136^{\circ}$

The welding used in this study was the electric welding and acetylene. It is very closely related to the electric current, toughness, welding defects and cracks which have a fatal effect on the security of the welded construction.

To get good quality of welding results, the research focuses on the properties of the material to be welded. Achieving the standards of welding techniques will help expand the scope of the use of welded joints and increase the size of the building construction to be welded [11].

\section{RESEARCH METHOD}

This type of research is experimental research. This was done to compare the results of the electric and Oxyacetylene welding in term of tensile strength, hardness and microstructure on a steel plate St.42. The observed object which was given a welding treatment was then measured using a tensile, hardness and microstructure tests. The results were then compared to the electric welding and welding Oxyacetylene. It was done to obtain accurate data and subsequent analysis with data analysis techniques for each test.

In testing the microstructure, it would be seen clearly whether the specimen surface is completely flat, smooth and shiny without scratches, and has undergone a proper etching [12]. Observations were carried out under an Olympus Metallurgical Microscope with optimal magnification, while the shooting was done with an additional tool Photomicrographic Olympus System. Microstructure testing conducted to observe and compare physically to the microstructure of each part of the test specimen. It was also conducted to observe the shape of the microstructure of specimens through welding.

\section{RESULTS AND DISCUSSION}

On the other hand, the tensile strength of the acetylene had a maximum strength of $58,2500 \mathrm{Kg} / \mathrm{mm}^{2}$ with the maximum force of $18,6400 \mathrm{~N}$. The differences in the average tensile strength of $=302,89600 \mathrm{~kg} / \mathrm{mm}^{2}$ with the maximum force difference of $=96,92667 \mathrm{~N}$.

However, the results of the analysis concluded that there was no significant difference. It meant that there was a difference of tensile strength and maximum force, but it did not have a significant difference.

Moreover, the level of hardness in the electric welds was in average of $936,5443 \mathrm{HV}$, and the hardness standards in acetylene welding resulted in the average of 902,5220 HV, with different numbers of $34,02233 \mathrm{HV}$. Analysis of the results of this study concluded that there was no significant difference.

Large steel grain pearlite microstructure electric welding had results of $66.8496 \mu \mathrm{m}$ and grain ferrite steel amounted to $29.3485 \mu \mathrm{m}$. On the other hand, the microstructure of steel grain pearlite through acetylene welding had results of $58,5267 \mu \mathrm{m}$ and grain ferrite steel amounted to $29,3585 \mu \mathrm{m}$. Analysis of the results of this study concluded that there was no significant difference. 


\section{CONCLUSION}

Based on the results of hypothesis testing and discussion of the results, the conclusions of this study are as follows the amount of electric welding tensile strength resulted in a maximum tensile strength of $361,1460 \mathrm{~kg} / \mathrm{mm}^{2}$ with a maximum tensile force of $115,5667 \mathrm{~N}$. The magnitude of the tensile strength in acetylene welding had a maximum tensile strength of $58,2500 \mathrm{Kg} / \mathrm{mm}^{2}$ with a maximum tensile force of 18,6400 N.2. The level of hardness in the electric welder welds was in the average of 936,5443 HV and the magnitude of hardness in acetylene welding was in the average of 902.5220 HV.3. The amount of steel grain pearlite microstructure electric welding resulted of $66.8496 \mu \mathrm{m}$ and grain ferrite steel amounted to $29.3485 \mu \mathrm{m}$. While the amount of steel grain pearlite microstructure acetylene welding resulted of $58.5267 \mu \mathrm{m}$ and grain ferrite steel amounted to $29.3585 \mu \mathrm{m}$.

\section{REFERENCES}

[1] S. Kalpakjian and S. Schmid, Manufacturing Engineering \& Technology. Pearson Education, 2013.

[2] Y. F. Sun, H. Fujii, N. Takaki, and Y. Okitsu, 'Microstructure and mechanical properties of dissimilar Al alloy/steel joints prepared by a flat spot friction stir welding technique', Mater. Des., vol. 47 , pp. 350 357, 2013.
[3] A. Macwan, V. K. Patel, X. Q. Jiang, C. Li, S. D. Bhole, and D. L. Chen, 'Ultrasonic spot welding of $\mathrm{Al} / \mathrm{Mg} / \mathrm{Al}$ tri-layered clad sheets', Mater. Des., vol. 62, pp. 344-351, 2014.

[4] Y. Y. Zhao, D. Li, and Y. S. Zhang, 'Effect of welding energy on interface zone of Al-Cu ultrasonic welded joint', Sci. Technol. Weld. Join., vol. 18, no. 4, pp. 354-360, 2013.

[5] W. Zhang, D. Sun, L. Han, and D. Liu, 'Interfacial microstructure and mechanical property of resistance spot welded joint of high strength steel and aluminium alloy with 4047 AlSi12 interlayer', Mater. Des., vol. 57, pp. 186-194, 2014.

[6] H. J. Park, D. C. Kim, M. J. Kang, and S. Rhee, 'The arc phenomenon by the characteristic of EN ratio in AC pulse GMAW', Int. J. Adv. Manuf. Technol., vol. 66, no. 5-8, pp. 867-875, 2013.

[7] P. T. Houldcroft and R. John, Welding and Cutting: A Guide to Fusion Welding and Associated Cutting Processes. Elsevier, 2001.

[8] L. Jeffus, Welding: principles and applications. Nelson Education, 2011.

[9] C. Poggio, M. Lombardini, S. Gaviati, and M. Chiesa, 'Evaluation of Vickers hardness and depth of cure of six composite resins photoactivated with different polymerization modes', J. Conserv. Dent., vol. 15 , no. 3 , p. $237,2012$.

[10] M. M. Smedskjaer, J. C. Mauro, and Y. Yue, 'Prediction of glass hardness using temperature-dependent constraint theory', Phys. Rev. Lett., vol. 105, no. 11, p. 115503, 2010.

[11] K. Masubuchi, Analysis of welded structures: Residual stresses, distortion, and their consequences, vol. 33. Elsevier, 2013.

[12] J. A. Jiménez and G. Frommeyer, 'Analysis of the microstructure evolution during tensile testing at room temperature of high-manganese austenitic steel', Mater. Charact., vol. 61, no. 2, pp. 221-226, 2010. 